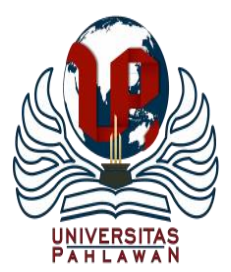

Edukatif : Jurnal Ilmu Pendidikan Volume 3 Nomor 1 Tahun 2021 Halm 174-179

EDUKATIF: JURNAL ILMU PENDIDIKAN

Research \& Learning in Education

https://edukatif.org/index.php/edukatif/index

\title{
Perbandingan Sistem Pendidikan Indonesia dan Jepang
}

\author{
Dian Montanesa ${ }^{1 凶}$, Firman $^{2}$, Riska $_{\text {Ahmad }^{3}}$ \\ Universitas Negeri Padang, Sumatera Barat, Indonesia ${ }^{1,2,3}$

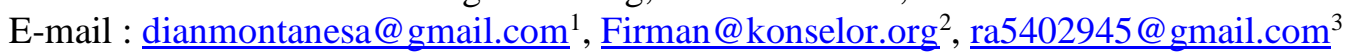

\begin{abstract}
Abstrak
Sistem pendidikan antara Indonesia dan Jepang berbeda. Sistem pendidikan di Indonesia dan di Jepang memiliki kelebihan dan kekurangan tersendiri. Saat ini sistem pendidikan di Indonesia perlu mendapat perhatian lebih karena menduduki peringkat 72 dari 77 negara. Di Indonesia telah lahir banyak ahli ilmu pendidikan yang mampu membawa sistem pendidikan di Indonesia ke arah yang lebih baik. Salah satu cara untuk membawa sistem pendidikan Indonesia ke arah yang lebih baik adalah dengan membandingkannya dengan negara dengan sistem pendidikan yang baik seperti Jepang. Di Jepang, mulai usia 0-3 tahun, anakanak lebih ditanamkan nilai moral, sopan santun, disiplin dan kesopanan. Ketika anak-anak di Jepang sudah memasuki kelas 4 SD, maka anak-anak tersebut mengikuti ujian yang tidak terlalu memberatkan siswa di sekolah. Indonesia bisa belajar banyak dengan sistem pendidikan di Jepang.
\end{abstract}

Kata Kunci: Sistem Pendidikan, Sistem Pendidikan Jepang, Sistem Pendidikan Indonesia.

\section{Abstract}

The educational system between Indonesia and Japan is different. The educational system in Indonesia and in Japan has its own advantages and disadvantages. Currently the education system in Indonesia needs more attention because it was ranked 72 out of 77 countries. In Indonesia, many educational science experts have been born who can bring the educational system in Indonesia to a better direction. One of the ways to bring Indonesia's educational system to a better direction is to compare it to a country with a good education system such as Japan. In Japan, from the age of 0-3, children are more instilled in moral values, manners, discipline and politeness. When children in Japan have entered grade 4 elementary school, then the children take the test which is not too burdensome for students at school. Indonesia can learn a lot with the educational system in Japan.

Keywords: The Educational Systems, Japan Educational Systems, Indonesia Educational Systems.

Copyright (c) 2021 Dian Montanesa, Firman, Riska Ahmad

$\triangle$ Corresponding author

Email : dianmontanesa@gmail.com

DOI : https://doi.org/10.31004/edukatif.v3i1.246

ISSN 2656-8063 (Media Cetak)

ISSN 2656-8071 (Media Online) 


\section{PENDAHULUAN}

Jepang memiliki sistem pendidikan yang baik di dunia, dikarenakan Jepang sudah memiliki banyak fasilitas yang mendukunga dan juga SDM yang mumpuni. Negara Jepang dijadikan patokan oleh negara berkembang sebagai kiblat untuk meningkatkan kualitas pendidikan (Johan 2018). Saat ini Indonesia merupakan negara negara yang memiliki kualitas pendidikan yang kurang baik, menurut PISA Negara berkembang yaitu negara Indonesia saat ini berada pada daftar ke 72 dari daftar 77 negara, ini dikarenakan kompetensi guru dan sistem pendidikan yang masih rendah di Indonesia (Sulfemi 2019).

Sistem pendidikan di Indonesia harus banyak belajar dari negara Jepang. Negara Jepang dari dulu hingga saat ini unggul dari segi teknologi dan juga dari segi pendidikannya, hal ini dikarenakan negara Jepang merupakan negara maju yang memiliki kualitas yang unggul (Johan 2018). Di Negara Jepang juga yang di ajarkan di sekolah itu bukan hanya tentang materi pelajaran, tetapi juga tentang norma-norma yang berlaku, seperti sopan santun, kejujuran, empati dan simpati (Connie Chairunnisa, Istayatiningtias et al. 2019). Di Jepang anak-anak sekolah dasar tidak akan mendapatkan ujian hingga sampai di kelas empat (Soetantyo 2013).

Di negara Jepang ujian yang akan dilaksankan sebelum anak mencapai kelas 4 Sekolah Dasar adalah ujian-ujian yang tidak berat, ujian yang sederhana yang tidak terlalu membebani anak-anak (Zarman 2017). Untuk usia dari 0-3 tahun pertama anak-anak di Jepang lebih diajarkan berkaitan dengan tata krama, sopan santun, membangun kepribadian yang baik dan mrngikuti nilai serta norma yang ada (Johan 2018). Di Negara Jepang kepribadian yang baik, disiplin, taat dengan peraturan tidak kalah penting dengan kepintaran yang di ajarkan di dalam kelas (Zarman 2017).

Di negara Indonesia masih banyaknya orangtua dan guru menuntu peserta didik dari segi akademis saja dan terkadang mengenyampingkan proses yang seharusnya juga dicapai dengan jalan yang baik. Di Indonesia lebih baik nilai tinggi dari pada kejujuran, contohnya banyak sekali guru yang membantu peserta didik untuk lulus Ujian Nasional (UN) dengan cara membagikan kunci jawaban agar akreditasi dari sekolah tidak turun, hal inilah yang membuat kualitas pendidikan di Indonesia semakin menurun (Zarman 2017).

Sejatinya yang harus dikembangkan dari diri seorang peserta didik itu tidak hanya ranah kognitifnya saja, tetapi juga ranah afektif dan psikomotorik (Asriati 2012). Pendidikan di Indonesia diyakini masih sangat konservatif, kurang terbaharui, dan masih jauh dari kata inovatif. Sangat penting adanya penigkatan yang signifikan bagi negara Indonesia dari segi sistem pendidikan baik dari kurikulum, kompetensi guru dan juga fasilitas yang merata yang ada di Indonesia (Connie Chairunnisa, Istayatiningtias et al. 2019).

Jepang bisa menjadi negara percontohan di bidang pendidikan, dikarenakan keunggulan-keunggulan yang dimiliki. Indonesia sebagai negara berkembang juga tidak salah belajar lebih banyak dengan negara Jepang bagaimana untuk menjadi lebih baik lagi dari sistem pendidikan yang ada (Sahban and SE 2018). Ada beberapa hal dari pola pendidikan di Jepang yang bisa dijadikan pedoman baru di Indonesia dalam rangka mencerdaskan kehidupan bangsa. Intinya agar negara Indonesia jauh lebih baik lagi kedepannya (Soetantyo 2013).

\section{METODE PENELITIAN}

Artikel ini membahas berkaitan dengan Perbandingan Sistem Pendidikan yang ada di Negara Indonesia dan di Negara Jepang, jenis metode yang digunakan adalah literatur research dengan cara mengumpulkan teori-teori yang relevan, yang sama atau linear dengan topik yang dibahas. 


\section{HASIL DAN PEMBAHASAN PENELITIAN}

\section{A. Sistem Pendidikan di Jepang}

Pendidikan di Jepang ada yang formal yaitu pendidikan di Sekolah, selanjutnya ada juga pendidikan yang berbasis moral yaitu merupakan sistem pendidikan yang bangun dari rumah dan yang ketiga sekaligus yang terakhir adalah pendidikan yang muncul dari masyarakat itu sendiri yang biasanya juga disebut pendidikan seumur hidup/ long life learner (Sahban and SE 2018). Di Jepang wajib belajar mulai dari usia 6 tahun hingga usia 15 tahun. Setiap keluarga yang memiliki anak pada rentang usia 6-15 tahun akan diberikan pemberitahuan untuk menyekolahkan anak-anak di sekolah (Fittryati 2020).

Di Jepang juga ada sekolah negeri yang biasanya disebut koritsu gakko. Sekolah negeri itu dikepalai atau diselenggarakan oleh pemerintah kota atau yang disebur prefektur. Tetapi ada beberapa juga sekolah yang dikelola oleh prefektur dan pemerintah pusat. Untuk sekolah swasta disebut juga dengan shiritsu gakko yang diselenggarakan oleh badan hukum (Novi Handayani 2017).

Di sekolah negeri biasanya siswa mulai masuk mulai dari hari senin hingga hari jumat, sedangkan sekolah swasta hingga hari sabtu. Di sekolah Jepang biasanya membagi setahun ajaran menjadi tiga caturwulan dan dibagi atas tiga musim, yaitu musim gugur/ fall, musim salju/ snow serta musim panas/ summer yang waktunya cenderung lama dan panjang. Di Jepang juga ada Taman Kanak-kanak yang biasanya disebut dengan youchien, ada juga sekolah hoikuen. Perbedaan antara youchien dengan hoikuen adalah apabila youchien jam sekolahnya mulai pukul 08.50-13.30, sedangkan youchien mulai dari 07.00-19.00 waktunya lebih lama dan lebih panjang, youchien diperuntukkan untuk anak-anak yang orangtuanya bekerja. Untuk anak-anak yang ingin dimasukkan ke youchien harus ada surat keterangan bahwa kedua orangtua bekerja (Muzaki 2020).

\section{B. Sistem Pendidikan di Indonesia}

Sistem pendidikan yang ada di negara Indonesia saat ini yaitu sistem pendidikan nasional. Sistem ini adalah memberikan siswa pengetahuan yang bersifat akademis, mengasah keterampilan kognitif, serta membina sikap positif kepada peserta didik sejak kecil (Asriati 2012). Sistem pendidikan Indonesia juga berorientasi pada nilai, sejak sekolah dasar peserta didik diberi pengajaran tentang kejujuran, kedispilinan dan rasa tenggang rasa. Di negara Indonesia juga menganut sistem pendidikan terbuka, disini maksudnya adalah siswa diminta untuk saling berkompetensi, mengembangkan kreatifitas yang dimiliki seluas-luasnya serta melakukan sesuatu yang lebih inovatif (Zarman 2017).

Sistem pendidikan di Indonesia beragam, beragam disini maksudnya adalah peserta didik merupakan siswa yang berasal dari background suku, bahasa, culture dan keyakinan (Baidhawy 2005). Di Negara Indonesia juga ada pendidikan formal dan non formal. Sistem pendidikan di Indonesia juga disesuaikan dengan perubahan zaman, pendidikan di Indonesia sebaiknya mengikuti perubahan era dan perubahan yang lebih inovatif dari waktu ke waktu oleh karena itu kurikulum di Indonesia sering berubah-rubah dikarenakan zaman yang berubah, seperti saat ini Indonesia sudah menggunakan K13 (Sudarsana 2016).

Jenjang pendidikan yang ada di Indonesia dimulai dari jenjang yang paling awal yaitu Pendidikan Anak Usia Dini PAUD, pendidikan PAUD ini diperuntukkan untuk anak-anak mulai dari usia 0-6 tahun, pendidikan PAUD diperuntukkan untuk anak-anak lebih mengembangkan, menumbuhkan baik dari segi jasmani dan rohani anak. Selanjutnya setelah PAUD akan dilanjutkan dengan pendidikan dasar ini jenjangnya dari kelas satu hingga kelas enam, sehingga total waktunya adalah enam tahun dan dilanjutkan dengan tiga tahun pada sekolah menengah pertama. Selanjutnya dilanjutkan dengan sekolah pendidikan menengah ini dikenal atau di sebut SMA selama 3 tahun waktu yang ditempuh. Pendidikan tinggi ini lebih luas, karena didalamnya ada D3, S1, S2, S3, dan spesialis (Suryaningrum, Ingarianti et al. 2016). 


\section{Perbandingan Sistem Pendidikan yang ada di Negara Indonesia dan di Negara Jepang}

Berikut ini akan dijelaskan perbandingan antar sistem pendidikan yang ada di Indonesia dengan sistem pendidikan yang ada di Jepang (Kurniawan 2017):

1) Jam Sekolah

Jam sekolah di Jepang di mulai dari pukul 8.00-15.00, sedangkan di Indonesia mulai dari pukul 07.15- 15.15, di Indonesia lebih lama satu jam. Di Jepang, apabila siswa datang terlambat maka akan dimintakan surat perjanjian untuk tidak mengulanginya lagi, di Indonesia siswa diberi hukuman seperti berdiri di tiang bendera, menyabut rumput, dll.

2) Etika dan Kedisiplinan

Murid atau siswa di Jepang baru mengikuti ujian mata pelajaran ketika sudah berada di grade empat atau setara dengan anak yang berumur 10 tahun, dikarenakan pada usia tiga tahun awal anak-anak diberikan pemahaman yang penting berkaitan dengan tataa cara berperilaku sehari-hari serta nilai sopan santun. Di Indonesia kedisiplinan masih harus ditingkatkan lagi begitu juga etika yang mengalami kemerosotan, bahkan di Indonesia sangat sulit bagi anak untuk mengantri ketika berbelanja.

3) Bidang Studi Pelajaran yang ada di Sekolah

Bidang studi yang dipelajari di sekolah yang ada di Jepang lebih sedikit dibanding dengan mata pelajaran yang ada di Indonesia, sehingga siswa bisa lebih fokus ke mata pelajaran yang ia senangi. Di Indonesia siswa diharapkan bisa menguasai banyak mata pelajaran, hal itu membuat siswa merasa tertekan dan merasa jenuh di Sekolah.

4) Pola Pikir Siswa

Murid di Jepang lebih banyak diajarkan bagaimana memecahkan suatu masalah/ problem solving, berpikir lebih kritis dalam proses pembelajaran. Di Indonesia anak-anak lebih sering diajak untuk menghafal oleh guru yang ada di sekolah.

5) Transportasi

Murid di Jepang lebih disarankan untuk berjalan kaki ke sekolah, menggunakan sepeda atau menggunakan sarana transportasi umum. Di Indonesia banyak siswa ke sekolah membawa motor dan mobil. Di Jepang anak-anak berjalan kaki atau mengendarai sepeda agar lebih sehat dan bersemangat pergi ke sekolah.

6) Perlengkapan Sekolah

Di sekolah anak-anak Jepang apabila memasuki kelas menggunakan sepatu khusus di sekolah agar kotoran tidak masuk ke dalam lantai sekolah, siswa juga menggunakan tas yang diberikan dari pihak sekolah. Di Indonesia anak-anak menggunakan barang-barang mewah untuk pergi ke sekolah dan itu memperlihatkan kelas anak-anak mana yang kaya dan kurang.

7) Menu Makan Siang

siswa di jepang setiap makan siang selalu memakan makanan yang sama dan juga minumminuman yang sama bersama dengan gurunya di dalam kelas. Di Indonesia siswa makanmakanan yang disukainya sesuai dengan seleranya, di Indonesia anak-anak bisa dengan bebas apakah ingin membawa makanan dari rumah atau jajanan sekolah.

8) Kebersihan Sekolah

Di jepang siswa setiap pulang sekolah jam 3 sore anak-anak bergotong-royong untuk membersihkan lingkungan sekolah yang disebut dengan O-Soji, tidak ada petugas sekolah yang bertugas untuk membersihkan lingkungan sekolah. Di Indonesia anak-anak membersihkan sekolah di pagi hari sebelum masuk ke kelas.

9) Seragam Sekolah 
Siswi di Jepang menggunakan pakaian seperti baju pelaut dan laki-lakinya menggunakan seragam seperti militer, bajunya tebal dan lengan panjang. Di Indonesia memiliki baju seragam yang berbeda-beda seperti merah putih, batik, dan pramuka.

\section{KESIMPULAN}

Sistem pendidikan Indonesia lebih mengedepankan kekayaan kognitif peserta didik, seperti nilai akademis, nilai ujian, dan nilai ulangan harian lainnya. Sistem pendidikan Indonesia kurang mengedepankan aspek afektif dan kognitif, hal ini perlu ditingkatkan lagi agar pendidikan di Indonesia lebih maju dan lebih berkembang ke depannya. Indonesia sebagai negara berkembang memiliki kesempatan yang luas untuk belajar dari negara-negara maju seperti negara Jepang, negara Jepang terkenal dengan sistem pendidikannya yang bagus dan juga teknologinya yang berkembang pesat.

Sistem pendidikan di Jepang merupakan sistem pendidikan yang unggul. Jepang sebagai negara maju memiliki kelebihan-kelebihan yang bisa ditiru oleh negara lain. seperti sistem pendidikan di Jepang yang juga memperhatikan aspek afektif, kognitif dan psikomototik. Sopan santun, tata krama, kedisiplinan serta menanamkan nilai-nilai norma sejak dini. Nilai lapor, nilai ujian tidak terlalu penting, hanya digunakan untuk seleksi masuk perguruan tinggi, masuk SMA ataupun masuk SMP.Perbandingan sistem pendidikan antara negara Indonesia dengan Jepang dijadikan untuk bahan evaluasi untuk kelanjutan kedepannya. Tidak dipungkiri bahwa Indonesia saat ini sudah mengalami kemajuan di bidang pendidikan, tetapi tetap harus dilakukan evaluasi agar pendidikan di Indonesia selalu ke arah kemajuan, sehingga mampu menciptakan generasi emas yang akan datang di masa depan.

\section{DAFTAR PUSTAKA}

Asriati, N. (2012). "Mengembangkan Karakter Peserta Didik Berbasis Kearifan Lokal Melalui Pembelajaran di Sekolah." Jurnal Pendidikan Sosiologi dan Humaniora 3(2): 106-119.

Baidhawy, Z. (2005). Pendidikan agama berwawasan multikultural. Erlangga.

Connie Chairunnisa, C., I. Istayatiningtias, et al. (2019). Pengembangan Model Pendidikan Karakter Di Sekolah Menengah Pertama. Mitra Wacana Media.

Fittryati, S. A. (2020). Perancangan sekolah pendidikan anak usia dini (paud) di Sidoarjo dengan pendekatan arsitektur ramah anak menurut permendikbud no. 137 tahun 2014, Universitas Islam Negeri Maulana Malik Ibrahim.

Johan, T. S. B. (2018). Perkembangan Ilmu Negara dalam Peradaban Globalisasi Dunia. Deepublish.

Kurniawan, C. (2017). Wawasan Pendidikan: Studi Komparatif Sistem Pendidikan Di Beberapa Negara Maju (Korea Selatan Dan Jepang).

Muzaki, A. (2020). Implementasi Manajemen Pendidikan Berbasis Sekolah Di Lembaga Pendidikan Formal $N U$ (Studi Kasus di SMK Ma'arif 2 Sleman).

Novi Handayani, N. (2017). Pengaluran dan Penokohan Dalam Novel Umibe No Kafuka Karya Haruki Murakami (Kajian Struktural)

Sahban, M. A. and M. SE (2018). Kolaborasi Pembangunan Ekonomi di Negara Berkembang. SAH MEDIA.

Soetantyo, S. P. (2013). Peranan dongeng dalam pembentukan karakter siswa sekolah dasar. Jurnal Pendidikan 14(1): 44-51.

Sudarsana, I. K. (2016). Pemikiran tokoh pendidikan dalam buku lifelong learning: policies, practices, and programs (Perspektif Peningkatan Mutu Pendidikan di Indonesia). Jurnal Penjaminan Mutu 2(2): 4453. 
179 Perbandingan Sistem Pendidikan Indonesia dan Jepang -Dian Montanesa, Firman, Riska Ahmad DOI : https://doi.org/10.31004/edukatif.v3i1.246

Sulfemi, W. B. (2019). Kompetensi Profesionalisme Guru Indonesia dalam Menghadapi MEA.

Suryaningrum, C., T. M. Ingarianti, et al. (2016). Pengembangan model deteksi dini anak berkebutuhan khusus (ABK) pada tingkat pendidikan anak usia dini (PAUD) di kota Malang. Jurnal Ilmiah Psikologi Terapan 4(1): 62-74.

Zarman, W. (2017). Ternyata Mendidik Anak Cara Rasulullah Mudah \& Efektif, Kawan Pustaka. 